would be to invite public disrespect.

MLS envy and the dangers surrounding it cannot be given too much attention. Successful resolution of this complex is the key to good relations with paraprofessionals, harmonious operations every- where in the library, and the eradication of ignorance. The last of these is, of course, the true mission of librarians. By dispelling MLS envy, librarians are educating and strengthening American society.

\title{
Staff training for a multi-database system
}

\author{
By Ramona J. Steffey \\ Automation Project Librarian \\ Vanderbilt University
}

In January 25, 1989, a new service was implemented for library users at Vanderbilt University. On that day a subset of the National Library of Medicine's MEDLINE database was first made available on public catalog terminals in the Medical Center Library and certain other branch libraries. This new service was the result of over two years of planning and development through an automation effort known as Vanderbilt's Enhanced Information Access Project, partially funded by a $\$ 750,000$ grant from the Pew Charitable Trusts.

A primary goal of the Enhanced Information Access (EIA) Project was to provide access to article level databases through the developing campus-wide broadband network. Inquiries were made to several major companies in the field of automation and an agreement was made with NOTIS Systems, Inc., to participate in this endeavor. Vanderbilt had already been successful in implementing NOTIS's Library Management System, having made the online catalog available in September 1985 and other modules (e.g. circulation, serials control, acquisitions) soon thereafter. Vanderbilt's objective in the EIA Project fit into NOTIS's long-range plan of adding multiple database access to its integrated online system.

Following a meeting with key NOTIS and Vanderbilt staff in January 1987, work began on what came to be known as Vandy 1. The results of Vandy $l$ are access to MEDLINE using NOTIS search commands and the capability of database selection and effortless switching from one database to another. This portion of the project was considered complete when the system became available to the public on January 25. The second phase of the NOTIS project, known as Vandy 2, will make three of the H.W.Wilson databases available in the same environment and is scheduled to be complete this spring. We have subscribed to the tapes for General
Science Index, Humanities Index, and Social Sciences Index.

NOTIS is expanding on the development work done with Vanderbilt and is marketing its "Multiple Database Access" product to other NOTIS customers. The finished product, which will be available this summer, provides the conversion programs for MEDLINE and H. W. Wilson and adds a greater flexibility to the system's inherent design, making it possible for a non-programmer to add new databases and modify screens. We at Vanderbilt have already started planning for loading tapes from the Center for Research Libraries as another option on our system. We will continue to work with NOTIS on further enhancements to the multiple database product.

Planning for staff training began long before the database became available to the public. As with the public catalog, online help screens were predicted to be the most important tools for training, both for staff and library patrons. Vanderbilt staff used as a base the LUIS screens provided by NOTIS. Modifications were made to highlight the unique features and fields of MEDLINE. Since we anticipated that many users would eventually be using the database from remote sites, we wanted the help screens to convey as much information as possible.

In addition to help screens, we prepared a brief brochure, or Quick Reference Guide, which could be given to patrons and made available at terminals. This guide covered the basic search commands, Boolean and positional operators, and tips for searching. Field qualifiers for keyword searching, the stopword list, language codes, and journal subset codes were listed. Also listed were the MeSH Check Tags and abbreviations for MeSH subheadings along with tips for searching these.

Training sessions began immediately after the 
database was put into production mode, just one week before public terminals were "turned on." In addition to library staff, certain members of the Medical Center staff (doctors, etc.) were invited to attend the training sessions. These staff, who were interested in evaluating the NOTIS MEDLINE product, had been identified through a survey conducted in October 1988. Most of them were already somewhat familiar with MEDLINE, having access to it on other systems such as BRS, DIALOG, NLM, and compact disc. Each of our training sessions lasted about two hours and consisted of lecture and hands-on experience.

The first point to be emphasized in the training sessions was the scope of the database; exactly what was in the file, when and how it would be updated, and how the users would know when the file was changed. The NOTIS system provides a "NEWS" screen for each database on which this type of information could be conveyed. At the time of the first training sessions, the file consisted of the entire 1988 MEDLINE file. We knew that it would soon be reloaded, so we told users that older records (published prior to 1988) would soon be deleted and the 1989 records would begin to be added. The users would be able to enter the "news" command to find out when these changes occurred and to keep up to date about the latest tapes loaded.

\section{Attention, authors!}

College \& Research Libraries News welcomes manuscripts submitted on diskette or via ALANET. The $C \triangleleft R L N e w s$ ALANET number is ALA0306. If you can upload it, I can download it, because ALANET translates text into pure ASCII files. If you don't have ALANET or you prefer to send a diskette, make sure it is formatted for MS-DOS; either 5.25-inch or 3.5-inch diskettes can be accepted.

We use Xywrite III+ for word processing, but we translate files from other major programs. When submitting a diskette with a file created by another word processing program, it is best to also include an ASCII text file.

Always send a paper copy of your manuscript along with the diskette, just in case we cannot read your file.

If you can neither send a diskette nor transmit via ALANET, submit three paper copies in a standard typeface such as Courier or Pica. Please avoid sending proportional or oversize typefaces.

Submit all materials to George M. Eberhart, Editor, C\&RLNews, ACRL/ALA, 50 E. Huron St., Chicago, IL 6061l.-GME.
A brief period was spent on the traditional author, title, and subject indexes and search commands. Sample searches emphasized how similar the MEDLINE guide screens and index screens were to those in Acom (Vanderbilt's name for the online catalog), and how movement from screen to screen and selection of records was accomplished in the same way in both databases. Some records were shown to get users familiar with the labelled record which identifies each of the fields displayed.

The format for authors in the MEDLINE database and the use of MeSH vocabulary for subject searching were discussed. Since Acom contains records with Library of Congress subject headings and Medical Subject Headings, there are two commands ( $\mathrm{s}=$ and $\mathrm{sm}=$ ) for subject searching; however, MEDLINE has only Medical Subject Headings so the $s=$ command is invalid. It was emphasized that only the English translations of titles were indexed and that title searches could be used when the exact title of a journal article was known. The titles of the journals themselves, as shown in the SOURCE field, are not searched by $\mathrm{t}=$; however users may locate articles published in a particular journal by keyword searching.

Users were shown how to switch back and forth from MEDLINE to Acom to determine if the library holds the journal identified in the MEDLINE record's SOURCE field. The technical services staff of the Medical Center Library have added the journal title abbreviation to an indexed MARC field for all of its titles, so users can be fairly successful in searching the form as it appears on the MEDLINE record. However, there are some journal titles indexed in MEDLINE which are held by other Vanderbilt libraries and have not been indexed in this way. Users were advised to search the full title, which could be identified in certain other reference sources, when they were unsuccessful searching by the abbreviated title on Acom.

A great deal of time was spent on keyword searching since it was predicted that this would be the primary means of accessing the database. Most of the library staff had recently attended keyword training on Acorn; skills taught in those sessions could be transferred to the new database.

However, many of the Medical Center staff were being introduced to the NOTIS keyword system for the first time. For both groups, there was much to cover regarding the fields which were available for keyword searching and tips for making the most of the keyword system. We attempted to learn how much and with which systems any of the attendees had previous online/ondisk experience and tailor the sessions for them, building on what they might already know.

Throughout the training period, the experimental nature of the MEDLINE project was emphasized. Library staff and Medical Center profession- 
als were encouraged to give us feedback on the system, its utility and its shortcomings. We intend to do a follow-up survey to those volunteers identified in the October survey and to provide forms at library terminals for in-house users to fill out. We will use the information gathered to determine possible changes in the content of the locally mounted database and number of access points to the records.
We are able to analyze transaction logs and other reports generated by the NOTIS system to see how much the various indexes are used and how successful users are with their searches. These tools are valuable ways to analyze the effectiveness of the training program. By identifying common problems and mistakes, future training will perhaps be more effective.

\title{
Trading places: Planning an
}

\section{international job exchange}

\author{
By David L. McChesney \\ Reference Librarian \\ University of Connecticut
}

Key elements in a successful job exchange overseas.

\section{D}

uring the 1987/88 academic year, I exchanged my position as reference librarian at the University of Connecticut with Terry Hanson, a social sciences librarian at Portsmouth Polytechnic, England. I offer my personal observations on the experience and job exchanges in general, with an emphasis on the reasons for an exchange and the detailed planning necessary.

Exchanging jobs requires risk-taking by the participants. Questions relating to many issues have to be investigated and resolved. Concerns on the quality of schools for the children, employment availability for spouses, and the responses to having complete strangers use one's house and personal property come to mind. The effect on library service and collections at the institutions involved, and the willingness of the library administrators to accept some of that risk are also issues that must be addressed.
The success of an exchange depends on careful and detailed planning. Before asking for official sanction, I'd recommend finding a specific librarian interested in an exchange and through correspondence document the commitment to the exchange; then present it to the administration. The planning for our exchange spanned two years and within this time we were able to develop a firm commitment and could resolve the problems that would have otherwise compromised the exchange. Since this was the first time anyone had exchanged in either of our libraries, we both felt committed to succeed so others could follow.

\section{Why exchange?}

What most attracted me was the challenge of changing jobs and learning new service and collection development methods. With the stagnant job 